\title{
The Steam Wells of California.
}

IHE utilisation of the steam of the soffioni of Tuscany as a source of mechanical power has steadily developed since 1904 when the first pioneer experiments were carried out at Larderello by Prince Ginori Conti. The remarkable results which have since been achieved were described in NATURE of Jan. 14 last. Similar sources of geothermal energy were first tapped in California in 1921, and since then several deep wells have been successfully sunk, some of them being superior both in pressure and steam output to any yet reported from Italy. The active region is known as 'The Geysers,' and lies on the western side of the St. Helena Range, one of the coast ranges of California. Along a line some twentyfive miles in length, which appears to mark a fault or shatter belt, hot springs, some of which are associated with quicksilver deposits, occur at intervals. There are no actual geysers at 'The Geysers,' but over an area of thirty-five acres the ground is dotted with hot springs and fumaroles and salt patches, and steam and gases are constantly seeping through the surface. A thorough investigation of the locality has been made by Dr. E. T. Allen and Dr. A. L. Day, and the results, beautifully published by the Carnegie Institution of Washington, 1 add very materially to our knowledge of subterranean supplies of magmatic steam.

The hot springs mainly occur where the groundwater drainage would naturally be expected to emerge; they are clearly related to a thin zone of groundwater and show seasonal variation with the rainfall. Some of the waters are acid, and contain acid sulphates produced by the oxidation of sulphuretted hydrogen. Others have become alkaline through their prolonged action upon the superficial rocks, this leading to the production of neutral sulphates, and allowing the alkaline character of the bicarbonates in the water to make itself felt. The fumaroles, known as the Smokestack, the Safety Valve, and the Steamboat, and the steam vents, are unrelated to the topography ; and neither these nor the artificial wells are affected by the weather. The exceptionally dry winter and spring of 1923-24 had no measurable influence on the steam flow, and all the evidence bearing on the origin of the steam points conclusively to a deep-seated magmatic source.

In all, eight wells had been sunk by June 1926, at depths gradually increasing from 200 to 650 feet. There is a marked temperature gradient, measurements revealing a rise of $130^{\circ}$ to $165^{\circ} \mathrm{C}$. within a depth of 500 feet from the surface. As at Larderello,

1 " Steam Wells and other Thermal Activity at 'The Geysers,' California." By E. T. Allen and A. L. Day. Carnegie Inst. of Washington, Pub. No. 378, 1927, pp. 106. and also at Katmai and Lassen National Park, the steam is supersaturated as it rises from the depths, but becomes saturated eventually after it has stood in a closed well for some time. "The opening of a well after the tools are removed presents an imposing spectacle. As the valve is opened steam and hot water rush violently out with a great roar, rising in successive leaps like a geyser and carrying a shower of sand. and loose rocks which bombard the steel frame of the derrick with a rattle like a fire of musketry. The column quickly reaches its maximum height of 200 to 300 feet, and in a few moments much of the excess water and loose debris are cleared out, leaving a huge jet of intensely hot roaring steam rushing from the well at high velocity, the noise of which can be heard for several miles and which at close range is absolutely deafening." Considering that the pioneers of so dangerous an enterprise had no previous experience of the kind and were even unaware that similar projects had been carried out in Tuscany, it is remarkable that the first wells were completed without serious accident.

Gases accompany the steam, making up between 1 and 2 per cent. of the whole. Carbon dioxide is, as usual, the dominant gas, but hydrogen and methane are present to the unusual extent of about 15 per cent. each, and there are smaller quantities of sulphuretted hydrogen, nitrogen, and ammonia. This is a characteristically volcanic assemblage, and taken together with the meagre supply of meteoric water, and the enormous volume of high-pressure steam rising in a superheated condition, it points indübitably to a magmatic source. In general, it is found that the deeper the well the hotter the steam, but not uniformly from well to well, indicating that the rock is not equally pervious to steam in all directions. The steam probably rises through a fault zone of shattered rocks which interpose a resistance that is generally, but not everywhere, completely effective. Only so can the difference in activity in the different fumarole and hot spring localities along the St. Helena Range be explained.

Following along the lines justified by their earlier investigations, the authors direct attention to the profound significance of the occurrence of volcanic gases as "the one thread logically connecting all phases of igneous activity, the cause alike of the volcanic explosions with their imposing steam clouds, the rise of lava in craters, the intense surface temperatures in some volcanic eruptions, the formation of fumaroles with their various characteristics, and finally of the heat of hot-spring waters and of the distinctive features in hot-spring areas.'

Arthur Holmes.

\section{Movements of British Industry and Trade.}

TWHE latest report of the Committee on Industry and Trade, entitled "Further Factors in Industrial and Commercial Efficiency," provides much useful information regarding the important and farreaching changes which have recently taken place in the relative prosperity and the geographical distribution of British industries.

Between 1901 and 1911 the number of persons employed in the main export industries increased by 20 per cent., as compared with an increase of $12 \frac{1}{2}$ per cent. in the total occupied population. In the next decade (including the abnormal War period) the total occupied population grew by $5 \frac{1}{2}$ per cent., but the rate of increase in the great industries was 21 per

No. 3053, VoL. 121] cent. In particular, coal mining and the metal and engineering trades increased much faster than industry as a whole. In the earlier decade the increase can be accounted for by the normal development of overseas trade. In the later period expansion was mainly in the munition industries, so that after the War Great Britain was left with an unduly expanded group of 'hypertrophied' industries. Statistics based on returns relating to the number of insured workers show that from 1923 to 1927 the number of persons engaged in the insured trades increased by nearly 6 per cent. from about $11 \frac{1}{4}$ millions to about 12 millions. This increase was, however, very unevenly distributed. Coal mining, iron and steel, general 